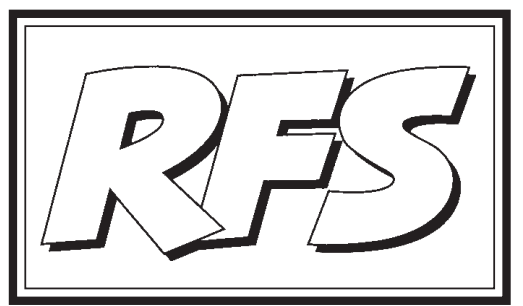

Revista de Fomento Social, 57 (2002), 535-538

\title{
Desarrollo Social y Paz Mundial
}

Conferencia de Obispos Católicos de Estados Unidos²

\section{CARTA AL PRESIDENTE BUSH SOBRE IRAK}

\section{Obispo Wilton D. Gregory}

13 septiembre 2002

Honorable George W. Bush

The White House

Washington D.C. 20500

\section{Estimado Sr. Presidente:}

En su reunión de la semana pasada, la Comisión Administrativa, de 60 miembros, de la Conferencia de Obispos Católicos de Estado Unidos me pidió que le escribiera sobre la situación en Irak. Apreciamos sus esfuerzos por centrar la atención del mundo en la necesidad de afrontar la represión en Irak

2 Puede consultarse el texto original inglés en la página Web oficial de la Conferencia Episcopal de los Estados Unidos: http://www.nccbuscc.org/sdwp/international/bush402.htm. 
536 CARTA DEL PRESIDENTE DE LA CONFERENCIA EPISCOPAL DE LOS ESTADOS UNIDOS AL PRESIDENTE BUSH

y en su carrera de armas de destrucción de masas, en claro desafío a las Naciones Unidas. La Comisión se reunió antes de que Vd. pronunciase su discurso en las Naciones Unidas, pero considero que es importante que le comunique nuestras graves reservas sobre la legitimidad moral de cualquier uso preventivo y unilateral de la fuerza militar para derrocar al gobierno de Irak.

Hace un año, mi predecesor, Obispo J oseph Fiorenza, le escribió respecto de la respuesta de los EE.UU. a los horrorosos ataques que conmemoramos la semana pasada (11 de septiembre). Le dijo entonces que, a nuestro parecer, el uso de la fuerza contra Afganistán podría justificarse, si se llevara a cabo de acuerdo con la justa normativa de guerra y como parte de un esfuerzo mucho más amplio y principalmente no militar para enfrentarse al terrorismo. Nosotros creemos que Irak es un caso diferente. Dados los precedentes y los riesgos implicados, encontramos difícil justificar la ampliación de la guerra contra el terrorismo a Irak, en ausencia de suficientes y claras pruebas de la implicación iraquí en los ataques del 11 de septiembre, o de un inminente ataque de carácter grave.

Las Naciones Unidas y la comunidad internacional tienen dos graves obligaciones morales: proteger el bien común en contra de cualquier amenaza iraquí para la paz, y de hacerlo de forma que cumpla las normas morales fundamentales. No albergamos ninguna ilusión respecto al comportamiento ni de las intenciones del gobierno iraquí. Los dirigentes iraquíes deben dejar su represión interna, cesar las amenazas a sus vecinos, impedir cualquier apoyo al terrorismo, abandonar sus esfuerzos por desarrollar armas de destrucción de masas, y cumplir con las resoluciones de la ONU. Supone una legítima y necesaria alternativa al uso de la fuerza militar unilateral, la movilización de las naciones del mundo para reconocer y enfrentarse a la amenaza de Irak para la paz y la estabilidad a través de la acción de la ONU, y un compromiso común para asegurarse de que Irak cumpla sus compromisos. La decisión de $\mathrm{Vd}$. de solicitar una acción por parte de la ONU es bien recibida, pero otras cuestiones sobre los fines y los medios también requieren una respuesta.

No hay respuestas fáciles. La gente de buena voluntad podría aplicar principios éticos y llegar a diferentes conclusiones prudentes, que dependen de su valoración de los hechos a valorar y de otras consideraciones. Nosotros llegamos a la conclusión, basándonos en los hechos que conocemos, que el uso de la fuerza preventivo y unilateral es difícilmente justificable en este momento. Tememos que el recurrir a la fuerza, en estas circunstancias, no 
cumpliría con las estrictas condiciones de la enseñanza católica para poder invalidar la fuerte presunción en contra del uso de la fuerza militar. De especial preocupación son los tradicionales criterios justos de guerra, autoridad apropiada, probabilidad de éxito, proporcionalidad e inmunidad de los no-combatientes.

Causa justa. ¿Cuál es el casus belli para un ataque militar a Irak? El Catecismo de la Iglesia Católica, que refleja los límites morales y legales ampliamente aceptados sobre cuándo la fuerza militar debe usarse, limita la causa justa a los casos en los que «el daño infligido por el agresor a la nación o conjunto de naciones (sea) duradero, grave, y seguro»(\#2309). ¿Existeclara y suficiente evidencia de una conexión directa entre Irak y los ataques del 11 de septiembre, o clara y adecuada evidencia de un inminente ataque de carácter grave?. ¿Es acertado ampliar dramáticamente los tradicionales límites morales y legales sobre la causa justa para incluir los usos preventivos de la fuerza militar para derrocar regímenes amenazadores, o para afrontar el problema de la proliferación de armas de destrucción de masas? ¿No debería hacerse una distinción entre los esfuerzos por cambiar el comportamiento inaceptable de un gobierno y los esfuerzos por acabar con la existencia de ese gobierno?

Legítima autoridad. La credibilidad moral sobre el uso de la fuerza militar también depende en gran medida de si existe una legítima autoridad para usar la fuerza para derrocar al gobierno iraquí. A nuestro parecer, unas decisiones de tanta envergadura requieren el cumplimiento de los imperativos constitucionales de EE.UU., un amplio consenso de nuestro pueblo, y algún tipo de autorización internacional, si es posible, del consejo de seguridad de la ONU. Es por esa razón quesu decisión de buscar la aprobación del congreso y de la ONU sea tan importante. J unto con la Santa Sede, estaríamos extremadamente escépticos sobre los usos unilaterales de la fuerza militar, especialmente dados los penosos precedentes que conllevan.

Probabilidad de éxito y proporcionalidad. El uso de la fuerza debe tener «serias perspectivas de éxito»y «no debe generar males y desórdenes más graves que el mal que se pretende eliminar»(Catecismo, \#2309). Una guerra contra Irak podría acarrear consecuencias impredecibles no sólo para Irak, sino para la paz y la estabilidad en el resto del Medio Oriente. ¿Tendría éxito una fuerza preventiva para frustrar las graves amenazas, o en su lugar, provocaría precisamente los ataques que pretende evitar? ¿Qué impacto tendría otra guerra sobre la población civil en Irak, a corto y largo plazo? ¿Cuánta gente inocente más sufriría y moriría, o quedaría sin hogar, sin las 
538 CARTA DEL PRESIDENTE DE LA CONFERENCIA EPISCOPAL DE LOS ESTADOS UNIDOS AL PRESIDENTE BUSH

necesidades más básicas, sin trabajo? ¿Se comprometerían los EE.UU. y la comunidad internacional a llevar a cabo la ardua tarea a largo plazo de asegurar una paz justa, o seguiría una Irak post-Saddam plagada de conflicto civil y represión, y seguiría siendo una fuerza desestabilizadora en la región? ¿El empleo de la fuerza militar llevaría a un conflicto y a una inestabilidad más amplios? ¿Una guerra contra Irak restaría valor a nuestra responsabilidad de ayudar a construir un régimen justo y estable en Afganistán, y debilitaría la coalición más amplia contra el terrorismo?

Las normas que gobiernan el conducto de la guerra. Al mismo tiempo que reconocemos la mejora de capacidad y los serios esfuerzos por evitar que los civiles no sean objetivos directos en una guerra, el uso de una masiva fuerza militar para derrocar al actual gobierno de Irak podría tener consecuencias incalculables para una población civil que ha sufrido tanto de la guerra, de la represión y de un embargo debilitante.

Planteamos estas penosas preguntas para contribuir al vital debatenacional sobre fines y medios, riesgos y alternativas, que reflejan nuestras responsabilidades como pastores y profesores. Nuestra valoración de estas cuestiones nos lleva a exhortarle a afanarse en buscar alternativas a la guerra. Esperamos que seguirá con los desafíos muy difíciles y frustrantes de forjar un amplio apoyo internacional para un nuevo enfoque más constructivo y efectivo para instar al gobierno iraquí para que cumpla sus obligaciones internacionales. Este enfoque podría incluir la continuación de los esfuerzos diplomáticos con la meta, en parte, de renovar inspecciones rigurosas y significativas; el cumplimiento efectivo del embargo militar; la continuación de sanciones políticas y económicas que sean mucho mejor enfocadas y que no amenacen la vida de los civiles iraquíes inocentes; el apoyo no-militar para aquellas personas en Irak que ofrecen auténticas alternativas democráticas; y otras formas legítimas para controlar e impedir las acciones agresivas iraquíes.

Con todo nuestro respeto, estando al borde de la guerra le instamos a dar un paso atrás y a colaborar en llevar al mundo a actuar al unísono para formular una respuesta global y efectiva a las amenazas de Irak, respuesta que se ajuste a los tradicionales límites morales del empleo de una fuerza militar.

Le saluda cordialmente

Most Reverend Wilton D. Gregory

Obispo de Belleville

Presidente

RFS 